\title{
Substance abuse behaviors among university freshmen in Iran: a latent class analysis
}

\author{
Kourosh Kabir ${ }^{1}$, Ali Bahari², Mohammad Hajizadeh ${ }^{3}$, Hamid Allahverdipour 4 , \\ Mohammad Javad Tarrahi ${ }^{5}$, Ali Fakhari ${ }^{4}$, Hossein Ansari ${ }^{6}$, Asghar Mohammadpooras ${ }^{4}$ \\ 'School of Medicine, Alborz University of Medical Sciences, Karaj, Iran; '² Department of Statistics and Epidemiology, Faculty of Health, Tabriz \\ University of Medical Sciences, Tabriz, Iran; ${ }^{3}$ School of Health Administration, Faculty of Health, Dalhousie University, Halifax, Canada; \\ ${ }^{4}$ Research Center of Psychiatry and Behavioral Sciences, Tabriz University of Medical Sciences, Tabriz, Iran; ${ }^{5}$ Department of Epidemiology and \\ Biostatistics, School of Public Health, Esfahan University of Medical Sciences, Esfahan, Iran; ${ }^{6}$ Health Promotion Research Center, Zahedan \\ University of Medical Sciences, Zahedan, Iran
}

OBJECTIVES: Substance abuse behaviors among university freshmen in Iran are poorly understood. This study aimed to identify, for the first time, subgroups of university freshmen in Iran on the basis of substance abuse behaviors. Moreover, it examined the effects of socio-demographic characteristics on membership in each specific subgroup.

METHODS: Data for the study were collected cross-sectionally in December 2013 and January 2014 from 4 major cities in Iran: Tabriz, Qazvin, Karaj, and Khoramabad. A total of 5,252 first-semester freshmen were randomly selected using a proportional cluster sampling methodology. A survey questionnaire was used to collect data. Latent class analysis (LCA) was performed to identify subgroups of students on the basis of substance abuse behaviors and to examine the effects of students' socio-demographic characteristics on membership in each specific subgroup.

RESULTS: The LCA procedure identified 3 latent classes: the healthy group; the hookah experimenter group; and the unhealthy group. Approximately $82.8,16.1$, and $2.1 \%$ of students were classified into the healthy, hookah experimenter, and unhealthy groups, respectively. Older age, being male, and having a family member or a close friend who smoked increased the risk of membership in classes 2 and 3, compared to class 1.

CONCLUSIONS: Approximately $2.1 \%$ of freshmen exhibited unhealthy substance abuse behaviors. In addition, we found that older age, being male, and having a close friend or family member who smoked may serve as risk factors for substance abuse behaviors.

KEY WORDS: Substance abuse, Risk-taking behaviors, University freshman students, Water-pipe smoking, Tobacco smoking, Iran

\section{INTRODUCTION}

Adolescence and youth are unique stages of life and growth that offer opportunities and challenges for health promotion [1]. Ado-

\section{Correspondence: Asghar Mohammadpoorasl \\ Research Center of Psychiatry and Behavioral Sciences, Tabriz \\ University of Medical Sciences, Shahid Bakeri Boul., Tabriz \\ 5167846184, Iran \\ E-mail:ampoorasl@gmail.com \\ Received: Mar 29, 2018 / Accepted: Jul 2, 2018 / Published: Jul 2, 2018 \\ This article is available from: $\mathrm{http}: / / \mathrm{e}-\mathrm{epih} . \mathrm{org} /$}

(C) This is an open-access article distributed under the terms of the Creative Commons Attribution License (http://creativecommons.org/licenses/by/4.0/), which permits unrestricted use, distribution, and reproduction in any medium, provided the original work is properly cited.

(C) 2018, Korean Society of Epidemiology lescents often undergo numerous changes in terms of major individual characteristics, as well as changes that are the starting point of several behaviors in adulthood, such as drug abuse, sexual activities [2], and other high-risk behaviors [3]. Thus, these stages provide exceptional opportunities for helping individuals to establish and adopt healthy behavioral patterns to promote their present and future health [4].

Substance abuse behaviors (smoking, alcohol, drugs, marijuana, and other prohibited drugs) can have negative impacts on the wellbeing and overall development of adolescents and youths [5]. Considering these behaviors during adolescence and youth is particularly important because they are associated with several causes of death and illness during these periods [6]. Moreover, due to the specific characteristics of youth, high-risk behaviors in this stage can have long-lasting negative effects on the development and over- 
all health of society. Thus, youth is considered to be a uniquely important period for investigating high-risk behaviors [7].

Drug abuse is a major public health problem among adolescents globally [8]. Tobacco leads to the deaths of 7 million people annually, and nearly $80 \%$ of smokers live in low- and middle-income countries [9]. Moreover, smoking hookah causes irreparable damage to various body organs [10].

Studies among university students around the world have reported prevalence rates of 8.6 to $28.6 \%[9,11,12]$ and 14.3 to $34.0 \%$ for cigarette and hookah smoking in the past 30 days, respectively [13-17]. A 2012 study of Iranian university students reported prevalence rates of $15.8,8.5,8.0$, and $7.6 \%$ for cigarette smoking, hookah smoking, alcohol use in the past month, and drug abuse, respectively [18]. Strong relationships exist between hookah, cigarette, and alcohol use among students [19]. Recent studies have also shown that high-risk behaviors usually co-occur (e.g., the cooccurrence of alcohol abuse and violence [20], alcohol abuse and high-risk sexual behaviors [21], alcohol abuse and smoking [22], and drug abuse and high-risk sexual behaviors [23]).

Entering college is associated with a sense of independence and separation from family among young adults, as college provides a new social environment where alcohol and drugs are commonly used for entertainment [24]. A study among freshmen college students in the US showed that hookah use in the past 30 days increased in the first academic year, and the highest prevalence of hookah use onset was in the first 2 months of academic instruction [25]. Freshmen are especially vulnerable to drug abuse [25], and the onset of drug abuse among students is typically in the first year of college [26], although the following years witness further increases in drug abuse [27].

Adolescents and youth constitute a significant percentage of the Iranian population [28]. The prevalence of drug abuse is low among Iranian students, but is increasing among younger ages (i.e., students in high school) [29-31]. Although previous studies have investigated drug abuse in Iran, no study is available on drug abuse behaviors, particularly among university freshmen. Furthermore, to the best of our knowledge, no study has examined the drug abuse behaviors of freshmen using latent class analysis (LCA). Thus, the present study aimed to investigate drug abuse behaviors among Iranian university freshmen using the LCA method.

\section{MATERIALS AND METHODS}

This cross-sectional study was conducted between December 2013 and January 2014 in 4 cities in Iran: Tabriz (the capital of East Azerbaijan Province), Qazvin (the capital of Qazvin Province), Karaj (the capital of Alborz Province), and Khoramabad (the capital of Lorestan Province). Multi-stage random sampling was used to select 5,252 first-semester freshman students. Students were selected using a random proportional cluster sampling methodology that considered the type of university and major. The academic year starts on September 23 at Iranian universities. Therefore, students were selected approximately 3-4 months after they entered university. All selected students were invited to complete a survey questionnaire designed to collect data on socio-demographic characteristics and risk-taking behaviors. A total of 4,940 (94.1\%) students completed the questionnaire and signed an informed consent form. Permission to conduct the study was obtained from the ethics committee of Tabriz University of Medical Sciences.

The survey questionnaire was tested on 132 freshman university students to examine its face validity and reliability (retest after 2 weeks). The pilot test input was used to modify the instrument/ questionnaire. A minimum Spearman's correlation coefficient of 0.81 was obtained. To enhance the validity of students' self-reports, they were assured of the strict confidentiality of their responses and the fact that they could not be recognized based on their responses. The participants also were informed about the voluntary nature of their participation in the study and their right to refuse or skip any questions.

To assess students' substance abuse behaviors, the 4 indicator variables of cigarette smoking, hookah smoking, alcohol consumption, and drug abuse were used. Participants were classified by cigarette smoking status as never smokers, experimenters (having smoked fewer than 100 cigarettes in one's lifetime regardless of current smoking status), and regular smokers (occasional users and regular smokers). Respondents were categorized by hookah smoking status as non-users, experimenters (those who had only tried hookah), occasional users, and regular hookah smokers (hookah use at least once per week). Participants were classified by alcohol consumption as never drinkers, experimenters, and those who had consumed alcohol at least once in the past month. Students were classified by drug abuse behavior as never and ever users (if the student had ever used any illicit drugs such as Ritalin, methamphetamine, ecstasy, cannabis, opium, or heroin).

\section{Statistical analysis}

LCA was used for data analysis. To perform LCA, the 4 observable variables (i.e., indicators) of cigarette smoking, hookah smoking, alcohol use, and drug abuse were used to assess substance abuse behaviors among students as a latent variable. After finalizing the model, we entered age, sex, marital status, residence status, having a family member who smoked, and having a close friend who smoked as risk factors in the LCA model. The risk factors were included into a latent class model to identify characteristics that predicted membership in the various subgroups (latent classes). A likelihood ratio test was used for hypothesis testing in LCA with risk factors. All analyses were performed using proc-LCA in SAS version 9.2 (SAS Institute Inc., Cary, NC, USA).

\section{RESULTS}

The participants' age ranged from 17.0 to 34.0 years (mean, $20.6 \pm$ 2.4 years). The majority of students in the sample were female (62.9\%) and $6.2 \%$ were married. Only $24.8 \%$ of students had close friend(s) who were smokers, and $25.5 \%$ had a family member who smoked. 
Of the participants, $54.5 \%$ were living with their parents and the remaining $45.5 \%$ were living in a dormitory or shared accommodation. A summary of students' substance abuse behaviors is presented in Table 1 . The prevalence of all the substance abuse behaviors was generally low, although hookah smoking was more prevalent than other substance abuse behaviors.

On the basis of the 4 substance abuse indicators (cigarette smoking status with 3 levels, hookah smoking status with 4 levels, alcohol consumption with 3 levels, and drug abuse with 2 levels), there were 72 possible response patterns. We attempted to fit the LCA models with 1-6 classes. The $\mathrm{G}^{2}$ statistic test and its p-value, Akaike information criterion, and Bayesian information criterion were computed for each LCA model. With the exception of the 3-classes model, all models were statistically significant at the 0.05 level, indicating that the estimated models were not equivalent to the population model. Based on the model selection criteria and the interpretability of the results of the models, it was concluded that the model with 3 latent classes was most appropriate for the data. The results of the LCA model with 3 classes model showed that

Table 1. Prevalence of substance abuse behaviors among first-semester university freshmen in Iran

\begin{tabular}{lcrr}
\hline & & \multicolumn{2}{c}{$95 \% \mathrm{Cl}$} \\
\cline { 3 - 4 } Variables & & $\mathrm{LL}$ & $\mathrm{UL}$ \\
\hline Cigarette smoking & & & \\
Never & $4,385(89.2)$ & 88.3 & 90.0 \\
Experimenter & $248(5.0)$ & 4.5 & 5.7 \\
Regular & $283(5.8)$ & 5.1 & 6.4 \\
Hookah smoking & & & \\
Never & $3,239(65.9)$ & 64.6 & 67.3 \\
Experimenter & $836(17.0)$ & 16.0 & 18.1 \\
Occasional user & $675(13.7)$ & 12.8 & 14.7 \\
At least once per week & $162(3.3)$ & 2.8 & 3.8 \\
Alcohol consumption & & & \\
Never & $4,482(90.9)$ & 90.1 & 91.7 \\
Experimenter & $253(5.1)$ & 4.6 & 5.8 \\
At least once in the past month & $196(4.0)$ & 3.5 & 4.6 \\
Drug abuse & & & \\
No & $4,708(96.3)$ & 95.8 & 96.8 \\
Yes & $180(3.7)$ & 3.2 & 4.3 \\
\hline
\end{tabular}

$\mathrm{Cl}$, confidence interval; LL, lower limit; UL, upper limit.
Table 3. The model of substance abuse behaviors with 3 latent classes and the corresponding risk factors among first-semester university freshmen in Iran

\begin{tabular}{|c|c|c|c|c|}
\hline \multirow[b]{2}{*}{ Variables } & \multicolumn{3}{|c|}{ Latent classes } & \multirow{2}{*}{$\begin{array}{c}\mathrm{p}- \\
\text { value }\end{array}$} \\
\hline & Healthy & $\begin{array}{l}\text { Hookah ex- } \\
\text { perimenter }\end{array}$ & $\begin{array}{c}\text { Un- } \\
\text { healthy }\end{array}$ & \\
\hline Prevalence (\%) & 82.8 & 16.1 & 2.1 & \\
\hline \multicolumn{5}{|c|}{ Indicators in each latent class } \\
\hline \multicolumn{5}{|l|}{ Cigarette smoking } \\
\hline Never & $0.982^{1}$ & $0.550^{1}$ & 0.000 & \\
\hline Experimenter & 0.012 & 0.243 & 0.101 & \\
\hline Regular & 0.006 & 0.208 & $0.899^{1}$ & \\
\hline \multicolumn{5}{|l|}{ Hookah smoking } \\
\hline Never & $0.788^{1}$ & 0.093 & 0.010 & \\
\hline Experimenter & 0.148 & 0.293 & 0.108 & \\
\hline Occasional user & 0.065 & $0.450^{1}$ & $0.573^{1}$ & \\
\hline At least once per week & 0.000 & 0.164 & 0.309 & \\
\hline \multicolumn{5}{|l|}{ Alcohol consumption } \\
\hline Never & $0.988^{1}$ & $0.627^{1}$ & 0.007 & \\
\hline Experimenter & 0.009 & 0.242 & 0.255 & \\
\hline $\begin{array}{l}\text { At least once in the past } \\
\text { month }\end{array}$ & 0.004 & 0.132 & $0.739^{1}$ & \\
\hline \multicolumn{5}{|l|}{ Drug abuse } \\
\hline No & $0.990^{1}$ & $0.890^{1}$ & 0.459 & \\
\hline Yes & 0.010 & 0.110 & $0.541^{1}$ & \\
\hline \multicolumn{5}{|l|}{ Covariates (odds ratio) ${ }^{2}$} \\
\hline \multicolumn{5}{|l|}{ Age } \\
\hline Crude & 1.00 & 1.49 & 1.32 & $<0.001$ \\
\hline Adjusted & 1.00 & 1.13 & 1.19 & $<0.001$ \\
\hline \multicolumn{5}{|l|}{ Male (ref: female) } \\
\hline Crude & 1.00 & 3.78 & 12.33 & $<0.001$ \\
\hline Adjusted & 1.00 & 1.59 & 1.88 & 0.002 \\
\hline \multicolumn{5}{|l|}{ Married (ref: single) } \\
\hline Crude & 1.00 & 0.85 & 1.91 & 0.26 \\
\hline Adjusted & 1.00 & 1.02 & 0.96 & 0.41 \\
\hline \multicolumn{5}{|l|}{ Living with parents } \\
\hline Crude & 1.00 & 0.67 & 0.81 & 0.005 \\
\hline Adjusted & 1.00 & 1.06 & 1.03 & 0.51 \\
\hline \multicolumn{5}{|c|}{ Having a family member who smoked } \\
\hline Crude & 1.00 & 2.99 & 4.77 & $<0.001$ \\
\hline Adjusted & 1.00 & 3.68 & 6.33 & $<0.001$ \\
\hline \multicolumn{5}{|c|}{ Having a close friend who smoked } \\
\hline Crude & 1.00 & 16.41 & 69.18 & $<0.001$ \\
\hline Adjusted & 1.00 & 9.10 & 48.49 & $<0.001$ \\
\hline
\end{tabular}

${ }^{1}$ Larger item-response probabilities to facilitate interpretation.

${ }^{2}$ Crude model: only 1 risk factor; Adjusted model: all risk factors.

Table 2. Comparison of LCA models with different latent classes according to the model selection statistics

\begin{tabular}{lccccccc}
\hline Latent statuses $(\mathrm{n})$ & $\begin{array}{c}\text { Parameters } \\
\text { estimated }(\mathrm{n})\end{array}$ & $\mathrm{G}^{2}$ & $\mathrm{df}$ & $\mathrm{p}$-value & $\begin{array}{c}\text { Maximum } \\
\text { log-likelihood }\end{array}$ & AIC & BIC \\
\hline 1 & 8 & $1,946.6$ & 63 & $<0.001$ & $-9,353.8$ & $1,962.6$ & $1,976.1$ \\
2 & 17 & 156.3 & 54 & $<0.001$ & $-8,378.7$ & 190.3 & 219.0 \\
3 & 26 & 57.8 & 45 & 0.10 & $-8,330.9$ & 109.8 & 153.7 \\
4 & 35 & 51.4 & 36 & 0.05 & $-8,319.7$ & 121.4 & 180.6 \\
5 & 44 & 48.8 & 27 & 0.006 & $-8,301.9$ & 136.8 & 211.2 \\
6 & 53 & 37.3 & 18 & 0.005 & $-8,294.2$ & 143.3 & 232.9 \\
\hline
\end{tabular}

LCA, latent class analysis; AIC, Akaike information criterion; BIC, Bayesian information criterion. 
the differences between the expected and observed frequency of response patterns were not statistically significant $\left(G^{2}=57.8 ; \mathrm{df}=45\right.$; $\mathrm{p}=0.10)$.

After finalizing the model, we entered age, sex, marital status, residence status, having a family member who smoked, and having a close friend who smoked as risk factors in the LCA model. Table 2 presents the prevalence of each latent class, item-response probabilities, and the odds ratios (ORs) of risk factors associated with latent class membership. The probability of membership in each latent class is shown in the first row of Table 3. Approximately $82.8,16.1$, and $2.1 \%$ of students were classified in the healthy, hookah experimenter, and unhealthy subgroups, respectively. The conditional probabilities of responses for each substance abuse behavior are listed in the middle rows in Table 3. These probabilities form the basis for the interpretation and labeling of the latent classes. Latent class 3, the unhealthy subgroup, was characterized by a high probability of responding with an advanced level for all the substance abuse behaviors. Individuals in this latent class were more likely to report that they had engaged in all the substance abuse behaviors investigated in this study. In contrast, those in latent class 1 , the healthy subgroup, were more likely to report not engaging in any of the substance abuse behaviors. Latent class 2, the hookah experimenter subgroup, had a high probability of reporting hookah smoking, but not other substance abuse behaviors.

The ORs of membership in each class, compared to the first class, for the independent variables are also reported in Table 3. As can be seen in the Table 3, a 1-year increase in the age of the respondent increased the risk of membership in classes 2 or 3 , compared to class 1. Similarly, being male increased the risk of membership in classes 2 or 3, compared to class 1 . Marital status and living with one's parents (in comparison to living in a dormitory or shared accommodation) did not change the risk of membership in classes 2 or 3. Moreover, having a family member or a close friend who smoked increased the risk of membership in classes 2 or 3 .

\section{DISCUSSION}

The results of this study indicated that the prevalence of cigarette smoking (experimenters and regular smokers), hookah smoking (occasional users and those who used hookah at least once per week), alcohol consumption (those who had consumed alcohol at least once in the past month), and drug abuse among university freshman students was $10.8,17.0,4.0$, and $3.7 \%$, respectively. These percentages are lower than have been reported for Iranian university students and high school students $[18,29]$. The higher prevalence of hookah smoking among university freshman students than the use of other substances may have been observed because hookah smoking in Iran generally starts during adolescence in an occasional manner before university, meaning that freshman university students are usually familiar with hookah smoking [32,33]. Moreover, hookah smoking is relatively common among all Iranian students, especially among university stu- dents $[15,18,32,34,35]$.

According to the final fitted model for investigating drug abuse behaviors, approximately $82.8 \%$ of the freshmen belonged to the healthy subgroup, while $2.1 \%$ belonged to the unhealthy subgroup. In contrast, in a recently conducted study in Tabriz, 77.1 and $86.2 \%$ of male and female students, respectively, were classified into the healthy subgroup, while 13.3 and $4.3 \%$ of male and female students, respectively, were classified into the unhealthy subgroup [18]. The higher rate of drug abuse behaviors in that study among university students may have been due to various factors related to the conditions and environment of the universities. A study by Skidmore et al. [36] concluded that freshmen were exposed to a higher risk of drug abuse. In addition, admission to a university is recognized as a time of particular vulnerability to drug abuse [25]. Other studies have also shown that the onset of drug abuse among students was mainly in the first year of university education, although the following years were also associated with an increase in drug abuse [26,27].

The results of this study indicated that males and older age had statistically significantly positive relationships with membership in classes 2 and 3 of drug abuse behaviors, compared to class 1 . These results are consistent with the findings of similar studies in Iran, which found that being male, being older, and having spent more time in the university environment were positively associated with drug abuse $[18,32,37,38]$. The relationship between male and drug use might be specific to the students and the drugs studied in this analysis. In other words, there might be no such relationship between sex and other types of drugs. For example, in some studies, the use of certain drugs, such as amphetamines, has been reported to be more prevalent among females [39].

A study by Mohammadpoorasl et al. [18] examined high-risk behaviors of Iranian students in 2011 and observed a positive and statistically significant relationship between being single and cigarette/hookah smoking among males. Similarly to a study by Sabahy et al. [32], the results of the present study showed no significant relationships between the marital status of students and drug abuse behaviors. In this study, single students exhibited fewer highrisk behaviors than the Iranian university students who participated in the study conducted by Mohammadpoorasl et al. [18]. As the current study focused on freshmen, while the study by Mohammadpoorasl et al. [18] focused on all university students, the lower rate of drug abuse (i.e., the tendency for students to report lower-ranked categories of drug abuse behavior) found in the present study may have been due to the shorter presence of freshman students in the university environment.

Various studies have demonstrated the role of parental support and discipline in reducing high-risk behaviors among young adults and students $[37,40,41]$. Family support is believed to be a major factor contributing to quitting drugs among students [42]. According to the findings of this study, although $45.5 \%$ of the freshman students were not living with their parents, no significant relationship was observed between living with one's parents and drug abuse behavior. This might mean that living far from one's parents and 
the lack of parental support among freshman students did not lead to higher drug abuse, whereas a longer stay in the university environment might change this relationship. According to Locke et al. [24], the sense of being apart from parents might be a reason associated with such changes in the environment and continuing to live in the new environment.

Based on the findings of this study, the presence of a smoker in the family was significantly related to membership in classes 2 and 3 of drug abuse behaviors, compared to class 1 . Previous studies have reported that the presence of a drug abuser in the family was positively associated with drug abuse among other family members [37,39]. In this study, the highest OR was found for the relationship between having an intimate drug-abusing friend and belonging to classes 2 or 3 . Previous studies have recognized the importance of this factor, which has a positive relationship with the onset of drug abuse, increased drug abuse, and other highrisk behaviors $[32,38,43]$.

A major strength of the present study is its large and representative sample. However, this study also has some limitations. First, although a cross-sectional study design provides evidence of associations between variables, it provides no evidence of causality. Second, the study relied on self-reported data. Although we went to great lengths to ensure confidentiality and anonymity, we had no way of assessing the underreporting of substance abuse behaviors. Third, we did not have information on the behaviors of the participants during adolescence. Therefore, it is difficult to determine whether the risk behaviors analyzed in the present study emerged after participants entered university or were maintained from adolescence.

The overall prevalence of drug abuse behaviors among Iranian university freshmen was found to be low, and only approximately $2.1 \%$ of freshmen showed an unhealthy pattern of substance abuse behaviors. In addition, we found that older age, being male, and having a close friend or family member who was a smoker may serve as risk factors for substance abuse behaviors.

\section{ACKNOWLEDGMENTS}

The authors would like to gratefully acknowledge the financial support for this study provided by Tabriz University of Medical Sciences. They also wish to thank all the participants of this study for their valuable cooperation and participation.

\section{CONFLICT OF INTEREST}

The authors have no conflicts of interest to declare for this study.

\section{ORCID}

Kourosh Kabir: http://orcid.org/0000-0003-0883-8820; Ali Bahari: https://orcid.org/0000-0002-4094-4992; Mohammad Hajizadeh: http://orcid.org/0000-0003-0029-6449; Hamid Allahverdipour: http://orcid.org/0000-0003-3700-6185; Mohammad Javad Tarrahi: http://orcid.org/0000-0001-7875-4572; Ali Fakhari: http://orcid. org/0000-0002-3731-7146; Hossein Ansari: http://orcid.org/00000003-2755-7864; Asghar Mohammadpoorasl: http://orcid.org/00000001-8403-1151

\section{REFERENCES}

1. Halfon N, Hochstein M. Life course health development: an integrated framework for developing health, policy, and research. Milbank Q 2002;80:433-479.

2. Mulye TP, Park MJ, Nelson CD, Adams SH, Irwin CE Jr, Brindis CD. Trends in adolescent and young adult health in the United States. J Adolesc Health 2009;45:8-24.

3. Coleman JC, Hendry LB. The nature of adolescence. 3rd ed. London: Routledge; p. 119-136.

4. Brindis CD, Park MJ, Valderrama LT, Lee CM, Margolis R, Kolbe LJ, et al. Improving the health of adolescents \& young adults: a guide for states and communities; 2004 [cited 2018 Jul 25]. Available from: https://eric.ed.gov/?id = ED493428.

5. Eaton DK, Kann L, Kinchen S, Shanklin S, Ross J, Hawkins J, et al. Youth risk behavior surveillance--United States, 2007. MMWR Surveill Summ 2008;57:1-131.

6. Cowell JM, Marks BA. Health behavior in adolescents. In: Gochman DS, editor. Handbook of health behavior research III. Boston: Springer; 1997, p. 73-96.

7. Lee LK, Chen PC, Lee KK, Kaur J. Violence-related behaviours among Malaysian adolescents: a cross sectional survey among secondary school students in Negeri Sembilan. Ann Acad Med Singapore 2007;36:169-174.

8. Greydanus DE, Reed WJ, Hawver EK. Public health aspects of substance use and abuse in adolescence. Int Public Health J 2016; 8:455-484.

9. Haddad LG, Malak MZ. Smoking habits and attitudes towards smoking among university students in Jordan. Int J Nurs Stud 2002;39:793-802.

10. Waziry R, Jawad M, Ballout RA, Al Akel M, Akl EA. The effects of waterpipe tobacco smoking on health outcomes: an updated systematic review and meta-analysis. Int J Epidemiol 2017;46:3243.

11. Koura MR, Al-Dossary AF, Bahnassy AA. Smoking pattern among female college students in Dammam, Saudi Arabia. J Family Community Med 2011;18:63-68.

12. Deressa W, Azazh A. Substance use and its predictors among undergraduate medical students of Addis Ababa University in Ethiopia. BMC Public Health 2011;11:660.

13. Almutairi KM. Predicting relationship of smoking behavior among male Saudi Arabian college students related to their religious practice. J Relig Health 2016;55:469-479.

14. Jawad M, Choaie E, Brose L, Dogar O, Grant A, Jenkinson E, et al. Waterpipe tobacco use in the United Kingdom: a cross-sectional study among university students and stop smoking practitioners. PloS One 2016;11:e0146799.

15. Abbasi-Ghahramanloo A, Rahimi-Movaghar A, Zeraati H, Safiri 
S, Fotouhi A. Prevalence of hookah smoking and its related factors among students of Tehran University of Medical Sciences, 2012-2013. Iran J Psychiatry Behav Sci 2016;10:e4551.

16. Zavery A, Qureshi F, Riaz A, Pervez F, Iqbal N, Khan JA. Water pipe (shisha) use and legislation awareness against shisha smoking among medical students: a study from Karachi, Pakistan. J Community Health 2017;42:461-465.

17. Martinasek MP, Haddad LG, Wheldon CW, Barnett TE. Beliefs and attitudes associated with hookah smoking among a United States college population. Respir Care 2017;62:370-379.

18. Mohammadpoorasl A, Ghahramanloo AA, Allahverdipour H. Risk-taking behaviors and subgrouping of college students: a latent class analysis. Am J Mens Health 2013;7:475-481.

19. Goodwin RD, Grinberg A, Shapiro J, Keith D, McNeil MP, Taha F, et al. Hookah use among college students: prevalence, drug use, and mental health. Drug Alcohol Depend 2014;141:16-20.

20. Proescholdt MG, Walter M, Wiesbeck GA. Alcohol and violence: a current review. Fortschr Neurol Psychiatr 2012;80:441-449 (German).

21. Snipes DJ, Benotsch EG. High-risk cocktails and high-risk sex: examining the relation between alcohol mixed with energy drink consumption, sexual behavior, and drug use in college students. Addict Behav 2013;38:1418-1423.

22. Hoeppner BB, Bidwell LC, Colby SM, Barnett NP. Smoking patterns and their relationship to drinking among first-year college students. Nicotine Tob Res 2014;16:743-752.

23. Cryan B, Perry D. Sexual orientation and health risk behaviors among Rhode Island public high school students, 2009. Med Health R I 2011;94:380-382.

24. Locke GW, Shilkret R, Everett JE, Petry NM. Interpersonal guilt and substance use in college students. Subst Abus 2015;36:113118.

25. Fielder RL, Carey KB, Carey MP. Prevalence, frequency, and initiation of hookah tobacco smoking among first-year female college students: a one-year longitudinal study. Addict Behav 2012; 37:221-224.

26. Arria AM, Caldeira KM, O'Grady KE, Vincent KB, Fitzelle DB, Johnson EP, et al. Drug exposure opportunities and use patterns among college students: results of a longitudinal prospective cohort study. Subst Abus 2008;29:19-38.

27. Arora A, Kannan S, Gowri S, Choudhary S, Sudarasanan S, Khosla PP. Substance abuse amongst the medical graduate students in a developing country. Indian J Med Res 2016;143:101-103.

28. Aghamohammadi S, Hajinabi K, Jahangiri K, Asl IM, Dehnavieh R. Population and mortality profile in the Islamic Republic of Iran, 2006-2035. East Mediterr Health J 2018;24:469-476.

29. Momtazi S, Rawson RA. Substance abuse among Iranian high school students. Curr Opin Psychiatry 2010;23:221-226.
30. Nahvizadeh MM, Akhavan S, Arti S, Qaraat L, Geramian N, Farajzadegan Z, et al. A review study of substance abuse status in high school students, Isfahan, Iran. Int J Prev Med 2014;5(Suppl 2):S77S82.

31. Mohammadpoorasl A, Ghahramanloo AA, Allahverdipour H, Augner C. Substance abuse in relation to religiosity and familial support in Iranian college students. Asian J Psychiatr 2014;9:4144.

32. Sabahy AR, Divsalar K, Bahreinifar S, Marzban M, Nakhaee N. Waterpipe tobacco use among Iranian university students: correlates and perceived reasons for use. Int J Tuberc Lung Dis 2011; 15:844-847.

33. Fielder RL, Carey KB, Carey MP. Hookah, cigarette, and marijuana use: a prospective study of smoking behaviors among firstyear college women. Addict Behav 2013;38:2729-2735.

34. Gathuru IM, Tarter RE, Klein-Fedyshin M. Review of hookah tobacco smoking among college students: policy implications and research recommendations. Am J Drug Alcohol Abuse 2015;41: 272-280.

35. Grekin ER, Ayna D. Waterpipe smoking among college students in the United States: a review of the literature. J Am Coll Health 2012;60:244-249.

36. Skidmore CR, Kaufman EA, Crowell SE. Substance use among college students. Child Adolesc Psychiatr Clin N Am 2016;25: 735-753.

37. Mohammadpoorasl A, Nedjat S, Fakhari A, Yazdani K, Rahimi Foroushani A, Fotouhi A. Smoking stages in an Iranian adolescent population. Acta Med Iran 2012;50:746-754.

38. Sah RB, Pradhan B, Subedi L, Karki P, Jha N. Epidemiological study of tobacco smoking behaviour amongst residents of the hill region of Nepal. Kathmandu Univ Med J (KUMJ) 2016;14:215-220.

39. Russell K, Dryden DM, Liang Y, Friesen C, O'Gorman K, Durec T, et al. Risk factors for methamphetamine use in youth: a systematic review. BMC Pediatr 2008;8:48.

40. Piko BF, Balázs MÁ. Authoritative parenting style and adolescent smoking and drinking. Addict Behav 2012;37:353-356.

41. Ennett ST, Foshee VA, Bauman KE, Hussong A, Cai L, Reyes HL, et al. The social ecology of adolescent alcohol misuse. Child Dev 2008;79:1777-1791.

42. Abdulghani HM, Alrowais NA, Alhaqwi AI, Alrasheedi A, AlZahir M, Al-Madani A, et al. Cigarette smoking among female students in five medical and nonmedical colleges. Int J Gen Med 2013;6:719-727.

43. Khosravi A, Holakouie-Naieni K, Mansournia MA, Mahmoodi M, Pouyan AA. Predictors of transition in smoking stages in Iranian adolescents: a probabilistic discrete event system model. Iran J Psychiatry Behav Sci 2017;11:e7670. 